\title{
Research Paper \\ Estimation Vulnerability and Resilience Indicators in Iran Economy
}

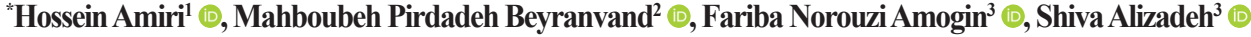

1. PhD. in Economics, Assistant Professor, Department of Economics and Islamic Banking, Faculty of Economics, Kharazmi University, Tehran, Iran.

2. MA. in Islamic Banking, Department of Economics and Islamic Banking, Faculty of Economics, Kharazmi University, Tehran, Iran.

3. MA. in Islamic Economy, Department of Economics and Islamic Banking, Faculty of Economics, Kharazmi University, Tehran, Iran.

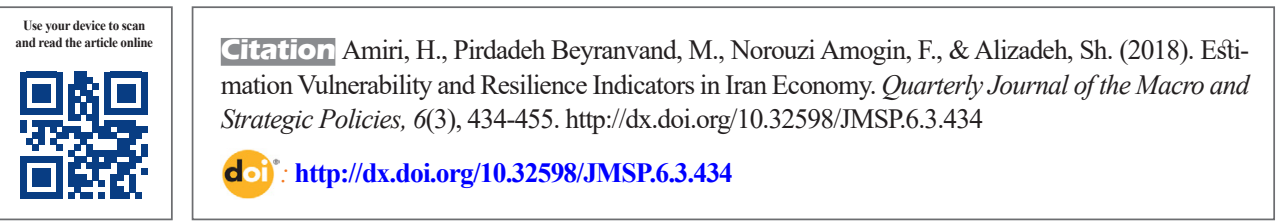

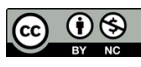

Funding: See Page 453

Received: 07 Mar 2018

Accepted: 15 Apr 2018

Available Online: 23 Sep 2018

Key words:

Resilience, Vulnerability, Resistance economics, Iran economy, Human capital

\section{A BSTRACT}

The main objective of this paper is to provide a method for analyzing and measuring the vulnerability and resilience index in Iran's economy. Economic resilience is the ability of a developed economy to block or mitigate the effects of negative shocks against what might intrinsically appear in an economy. The paper covers four aspects of macroeconomic stability, microeconomic market efficiency, government and social development, and examines Iran's economic viability and vulnerability index during the period of 1996-2016. The estimated indicators in this study are based on the selected variables of Bjerjalo et al. (2008) model. The results of this study indicate that from 1996 to 2004 and also from 2006 to 2014 and 2016 the net had a negative resilience, but this index was positive in 2005 and 2015. The most important reason for the positive value of this indicator in these two years were the existence of good governance and human development. In addition, both indicators of vulnerability and volatility have increased over the past few years, but the index of vulnerability is more than the resilience index, which indicates an increase in the degree of economic vulnerability in the Iranian economy.

JEL Classification: $\mathrm{CO} 1 \mathrm{C} 23$

* Corresponding Author:

Hossein Amiri, PhD.

Address: Department of Economics and Islamic Banking, Faculty of Economics, Kharazmi University, Tehran, Iran.

Tel: +98 (912) 4396993

E-mail: hossienamiri@gmail.com 


\section{برآورد شاخصهاى آسيبيذيرى و تابآورى در اقتصاد ايران}

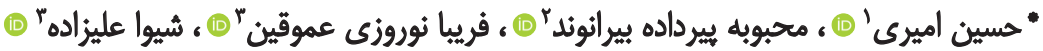

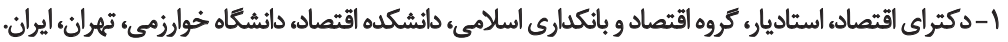

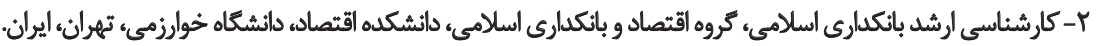

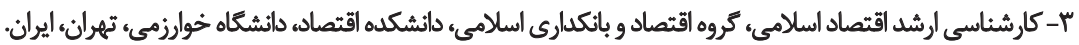

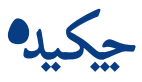

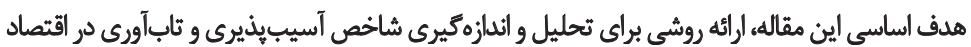

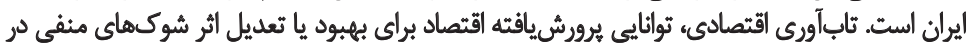

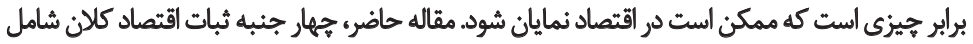

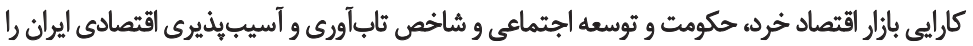

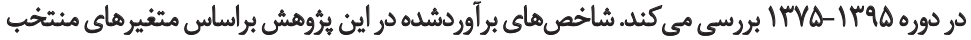

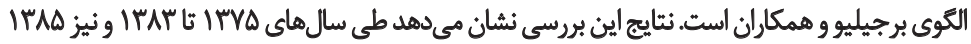

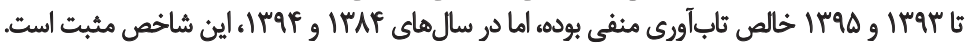

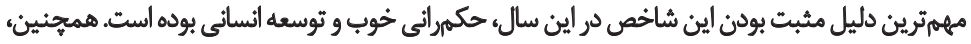

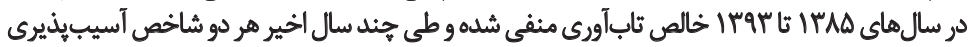

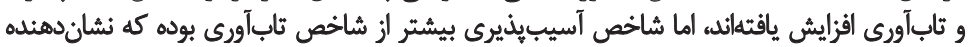

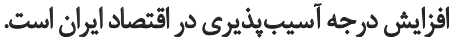
طبقهبندى CO1،C23:JEL

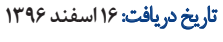
تاريخيذيرش:ع فورودين

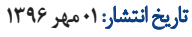

كليدوارهها:

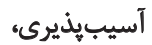
تاب/ورى، اقتتصاد

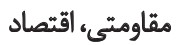

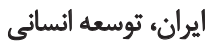




\section{dolo.}

فضاى امروز اقتصاد ايران، شاهد رويدادهاى منحصربهفرد اقتصادى است كه وقوع برخى از آنها تاكنون در دنيا

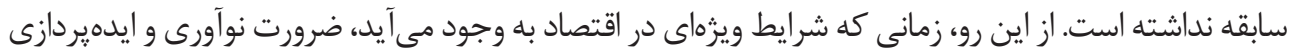

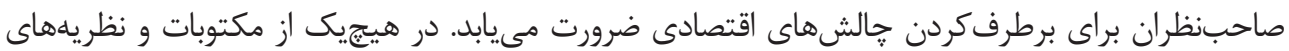

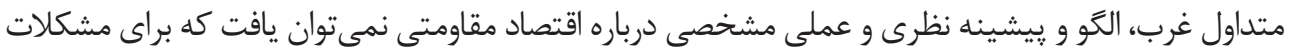

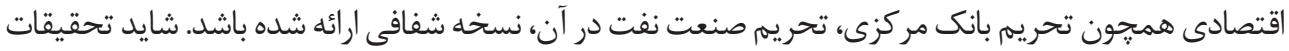

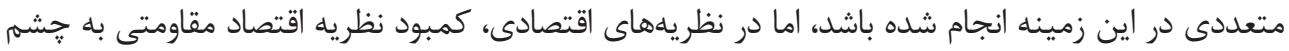

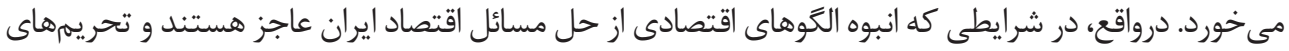

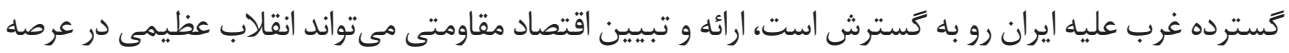

اقتصاد ايران ايجاد كند.

اقتصاد مقاومتى براى مقابله با تحريممهاى بينالمللى مطرح شده است. در حال حاضر، اقتصاد ايران بايد بر اساس

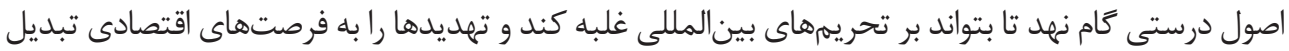

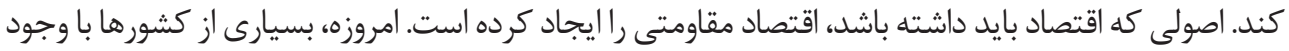

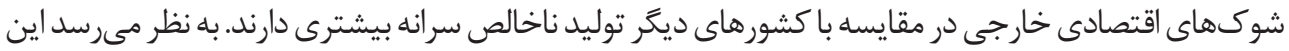

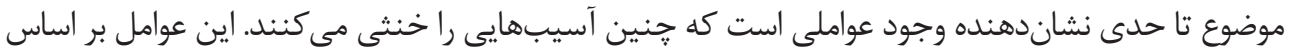

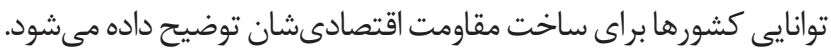

با توجه به اهميت مسئله اقتصاد مقاومتى براى دستيابى به اقتصادى مقاوم و پايدار، اين يروهش به تدوين و

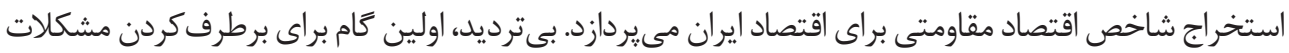

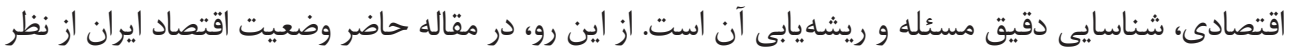

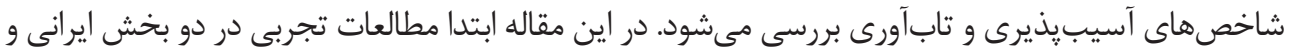

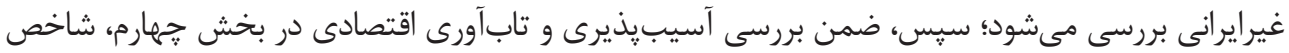

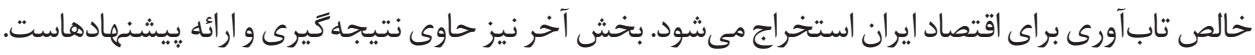

\section{1- ادبيات موضوع}

مرورى بر ادبيات موضوع اقتصاد مقاومتى در سطح جهان نشاندهنده جامعيت و قدمت طولانى اين مفهوم

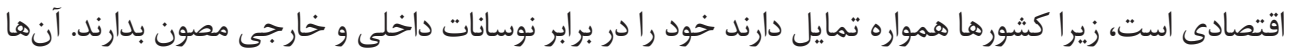

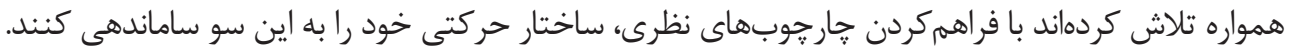

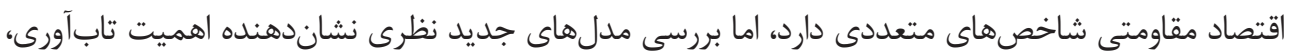

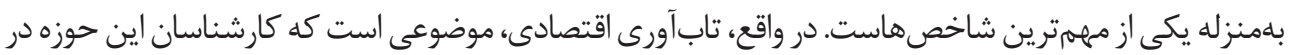

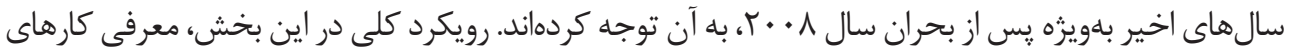

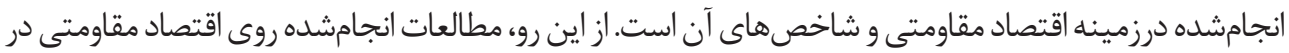


دو بعد داخلى و خارجى بررسى مىشود.

|- - - - مطالعاث داخلي

با توجه به اهميت اقتصاد مقاومتى در اقتصاد ايران، تحقيقات متعددى انجام شده است كه در ادامه ذكر

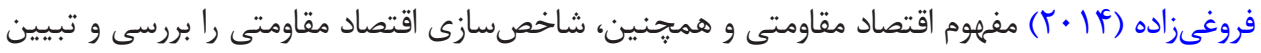

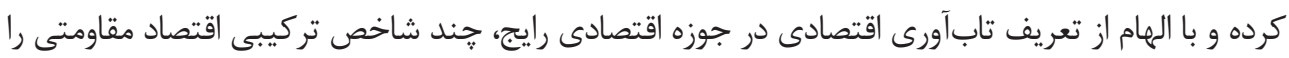

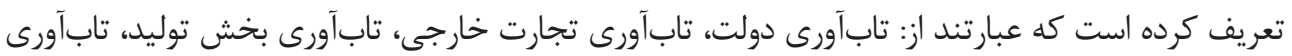

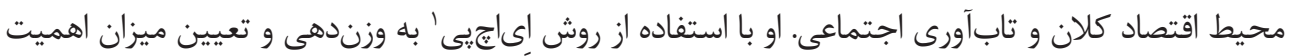

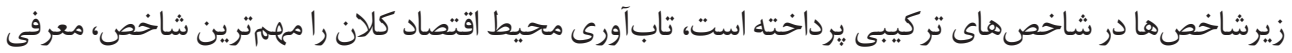

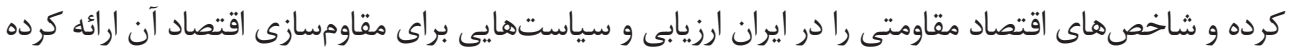

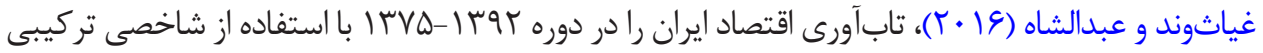

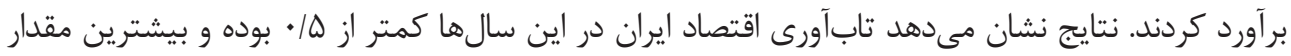

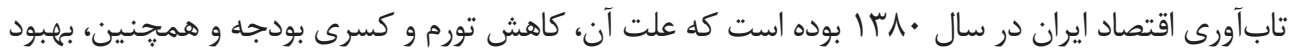

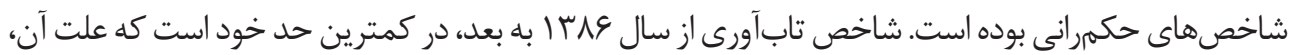

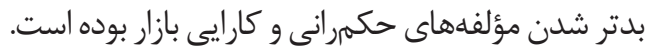

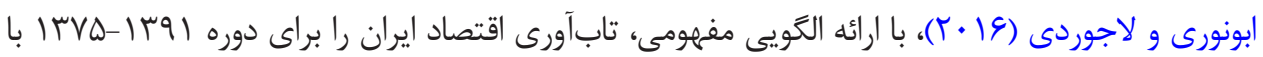

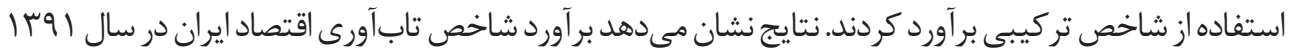

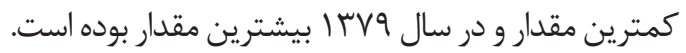

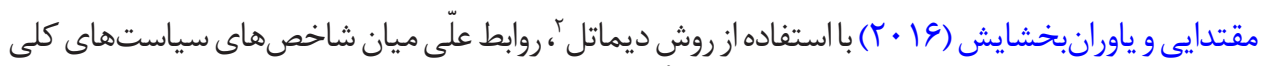

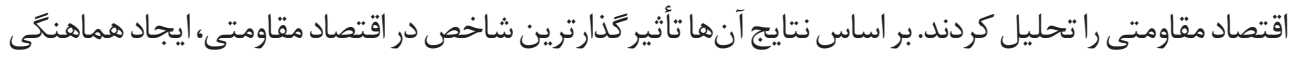

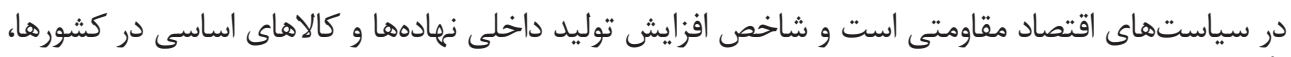

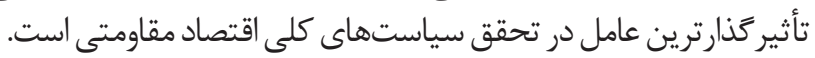

جار

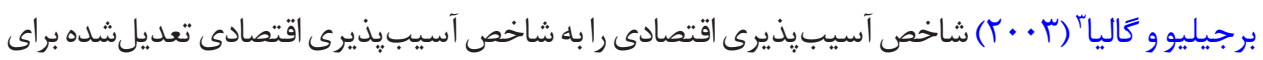

1. AHP

2. DEMATEL (Decision-Making Trial and Evaluation)

3. Briguglio and Galea 


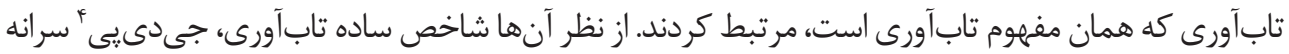

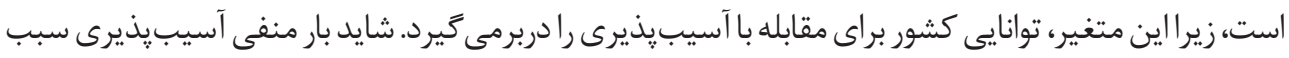

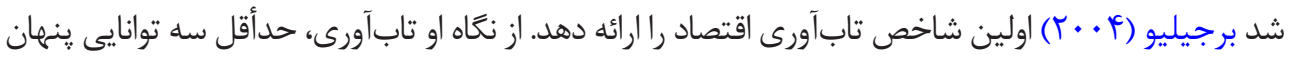

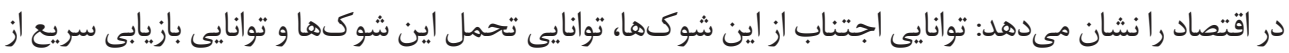
شوكهاى اقتصادى تخريب كننده بيرونى.

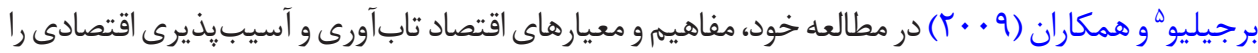

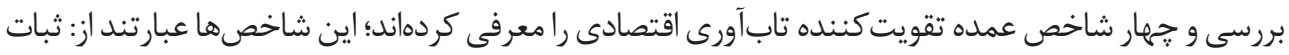

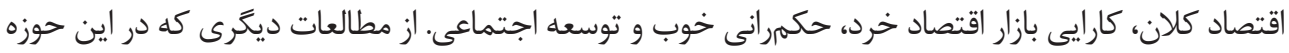

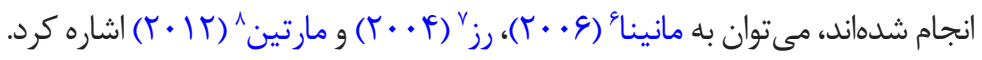

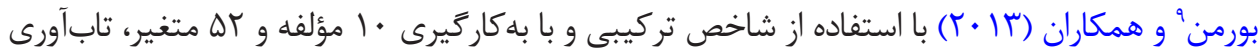

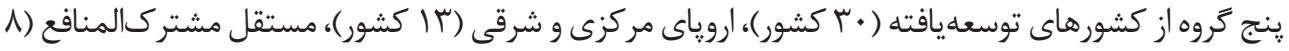

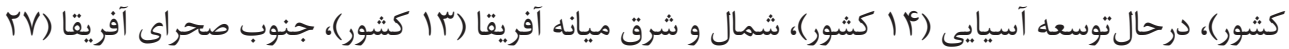

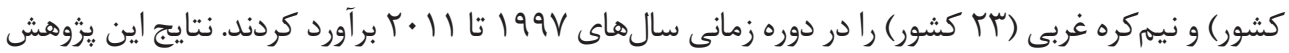

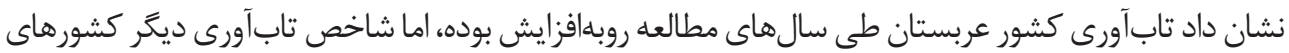

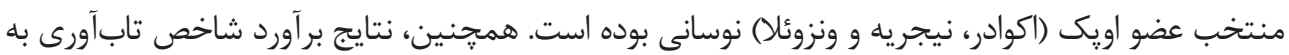

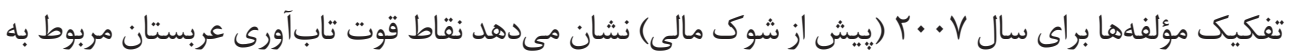

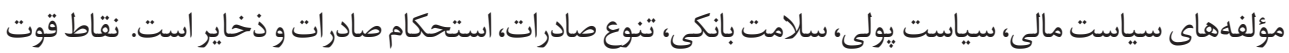

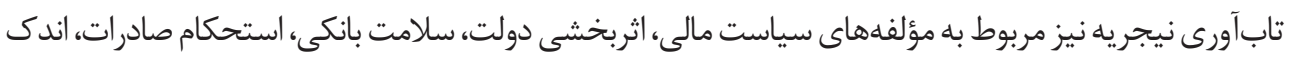

$$
\text { بودن بدهى خارجى خصوصى و ذخاير بوده است. }
$$

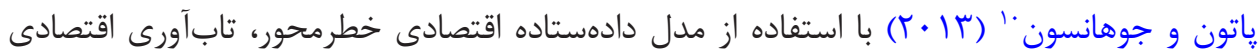

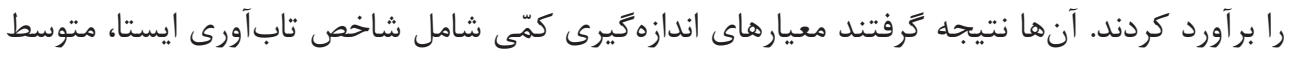

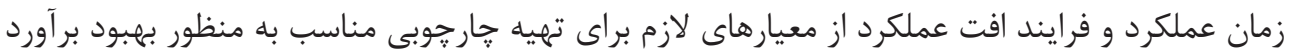

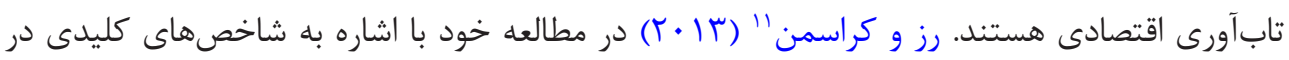

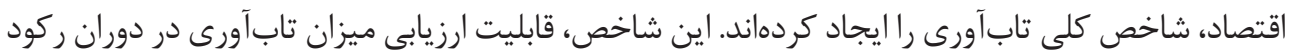

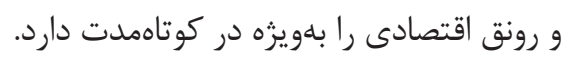

4. Gross Domestic Product (GDP)

5. Briguglio

6. Manyana

7. Rose

8. Martin

9. Boorman, et al.

10. Paton and Johnston

11. Rose and Krausmann 


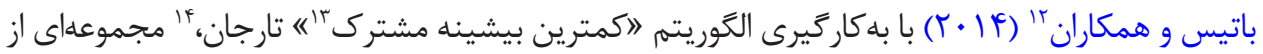

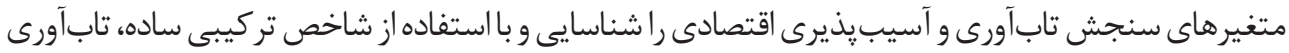

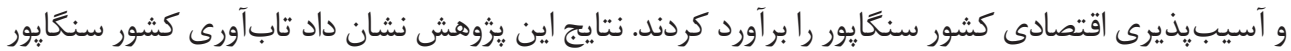

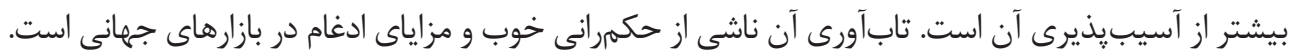

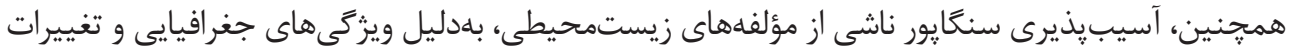
آبوهوايى است.

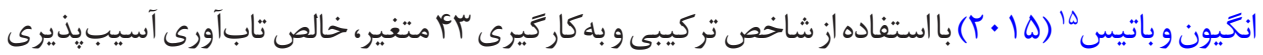

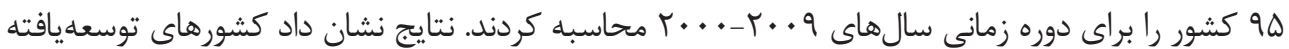

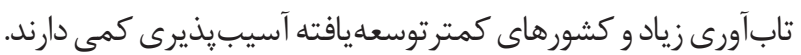

در زمينه اقتصاد مقاومتى مطالعات متعددى انجام شده است كه در بيشتر آنها علاوه بر تبيين مفهوم اقتصاد

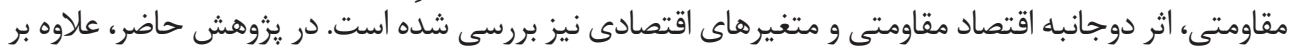

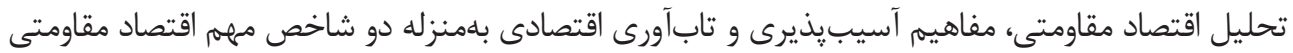

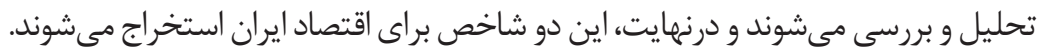

\section{ا-" - مبانى نظرى}

بررسى اقتصاد كشورهاى مختلف نشان مىدهد برخى كشورها علاوه بر آسيب ٍذير بودن، توليد ناخالص

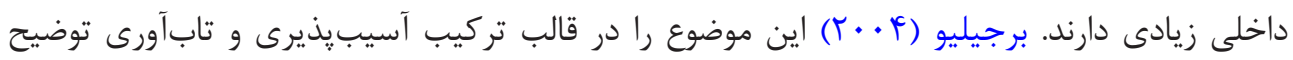

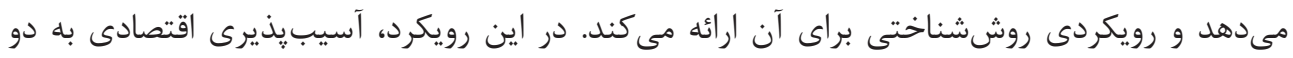

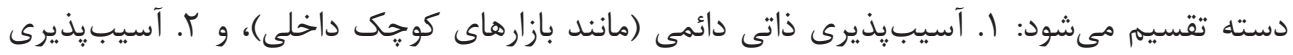

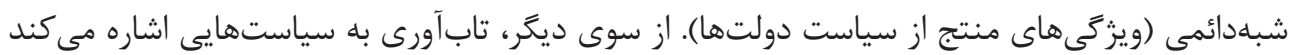

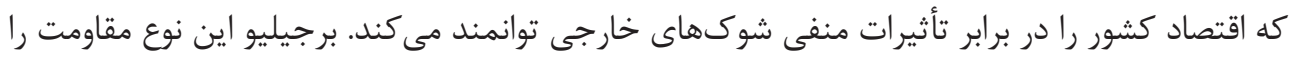

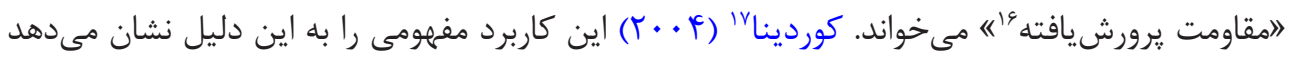

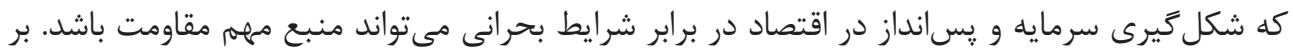

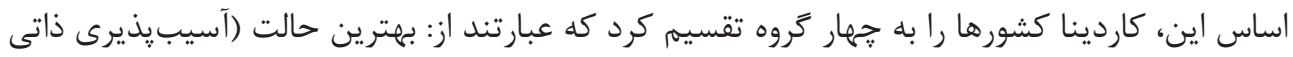

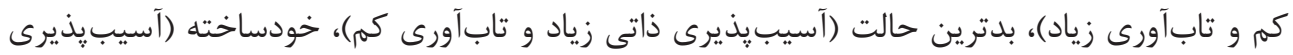

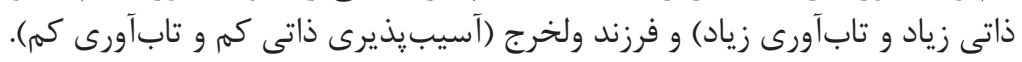

12. Bates et al.

13. The smallest common background

14. Tarjan

15. Angeon and Bates

16. Nurtured resilience

17. Cordina 
كشورهاى خودساخته (خوداتكا)، آنهايى هستند كه آسيبزيذيرى ذاتى زيادى دارند، اما با اقتباس

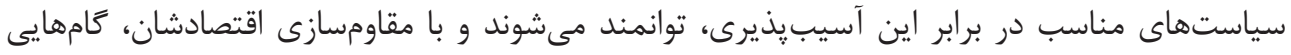

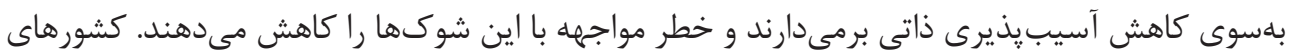

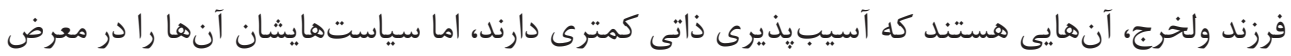

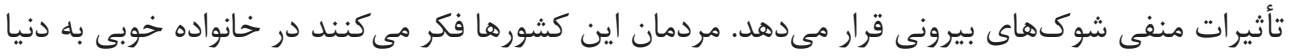

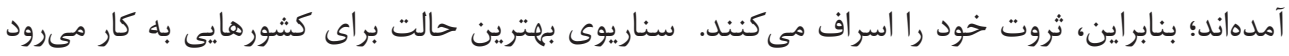

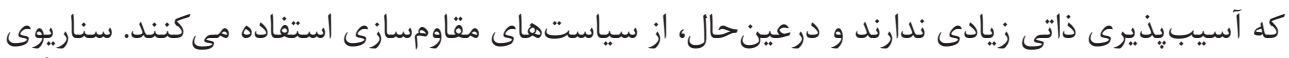

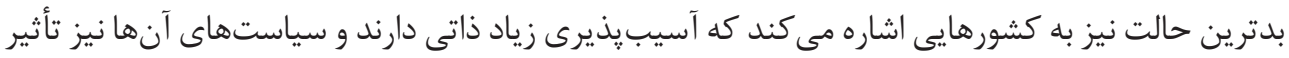

$$
\text { منفى آسيب يذيرى را بيشتر مى كند (برجيليو، كوردينا، فاروكيا و ولا، } 9 \text { • . ب). }
$$

جهار سناريوى مذكور در جدول شماره ا نشان داده شدهاند. محورها بهترتيب، آسيب پيذيرى اقتصادى ذاتى و

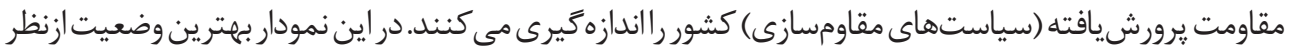

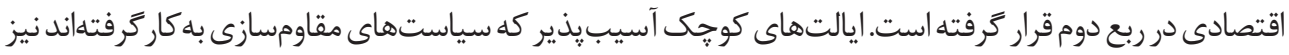

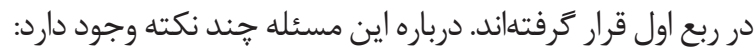
روش تعريف آسيبزٍيرى برحسب ويزگى هاى ذاتى و تاب آورى برحسب سياستها، مشمول تغيير است. اين

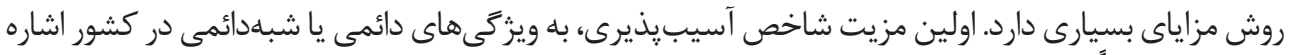

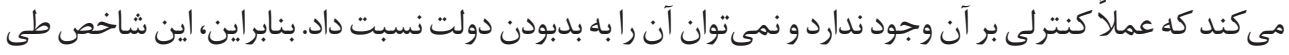

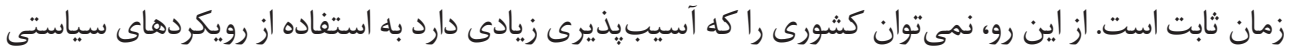

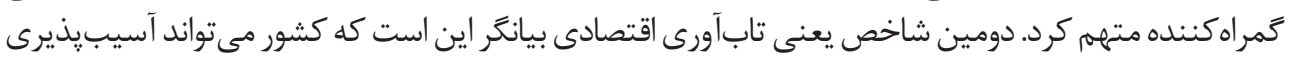

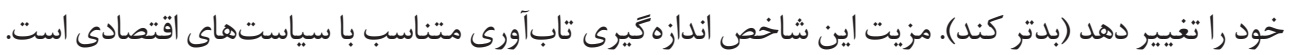

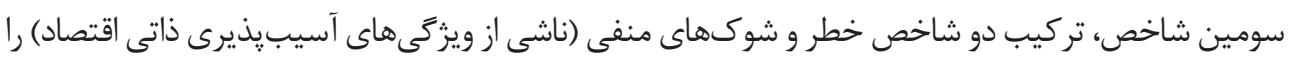

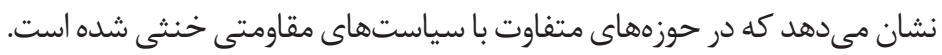
اصولاً آسيبزيذيرى ذاتى دائمى و شبهدائمى به اين موضوع اشاره مى كند كه نبايد انتظار داشت كشورهايى كه بيشتر درمعرض آسيبها و شوكهاى خارجى قرار دارند، بهطور عمودى در امتداد ربعهاى جدول شماره إنى

جدول ا. سناريوهاي شاخص آسيبذيرى و ثابآورى اقتصادى Lان

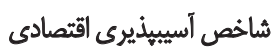

بدترين حالت

فرزند والخرج
هُودساخته

بهترين حالت
شاخص

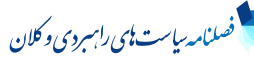




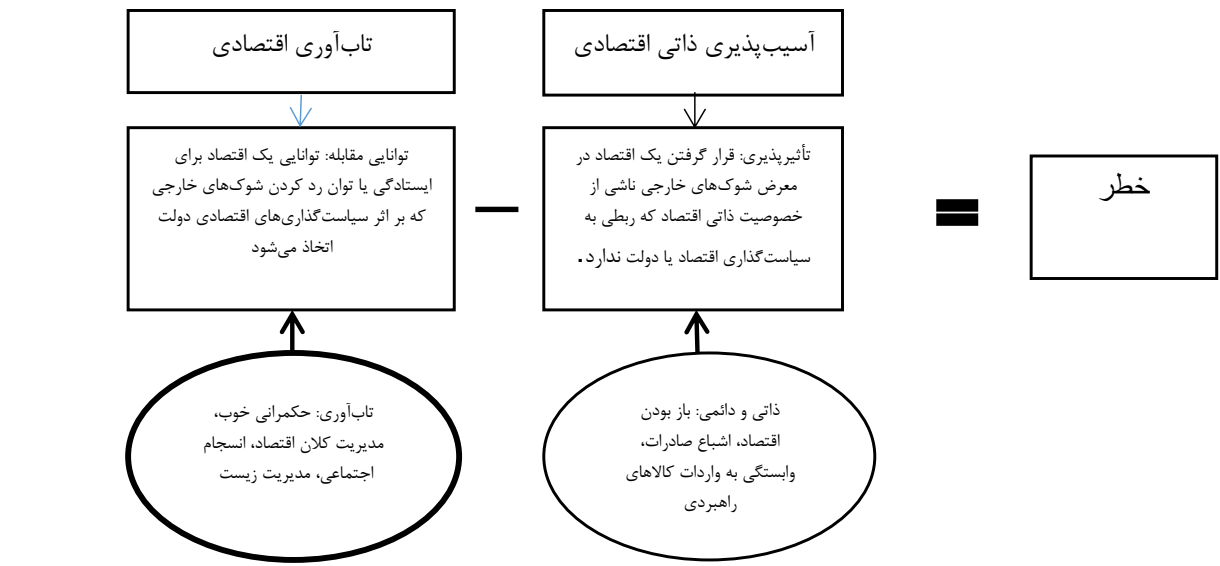

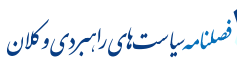

تصوير ا. خطر تخريب اقتصاد

حركت كنند. در واقع، اين كشورها با تغيير سياستهاى اقتصادى، بين دستههاى بدترين حالت و خودساخته يا بهترين حالت و فرزند ولخرج جابهجا شوند.

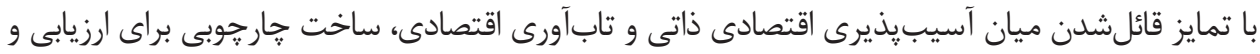

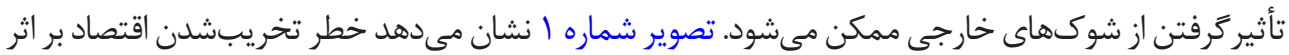

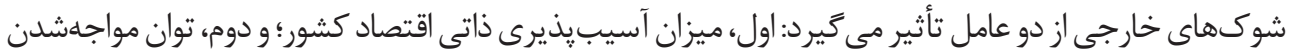

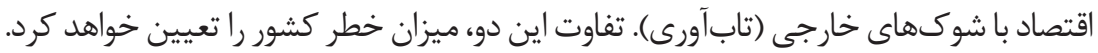

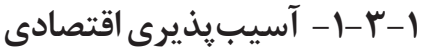

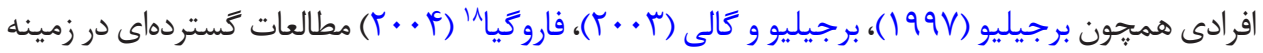

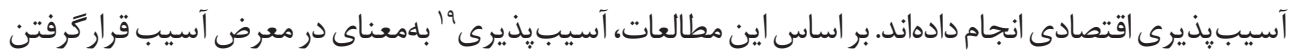

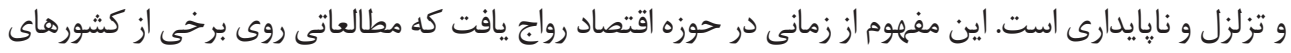

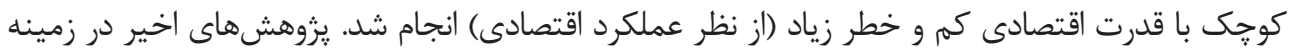

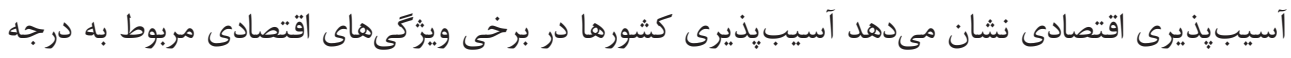

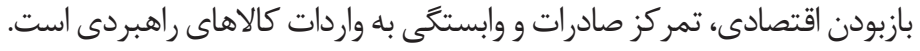

بازبودن اقتصاد: بازبودن اقتصاد را مىتوان با مجموع صادرات و واردات به توليد ناخالص داخلى اندازهذيرى

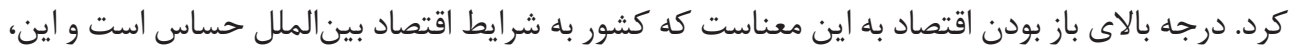

18. Farrugia

19. Vulnerate 


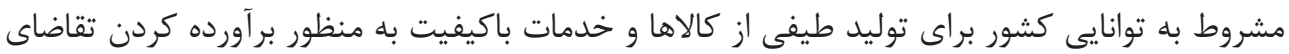

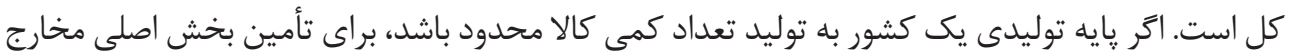

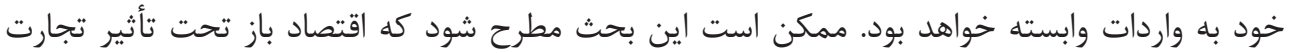

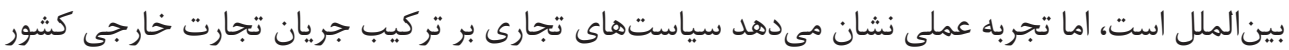

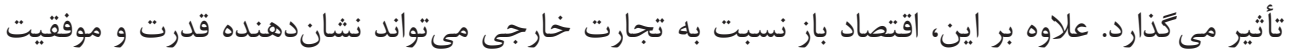

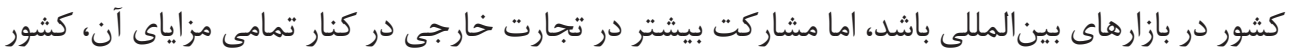

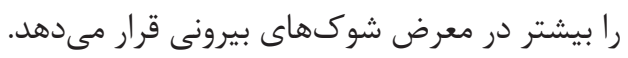

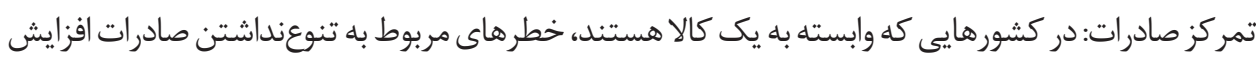

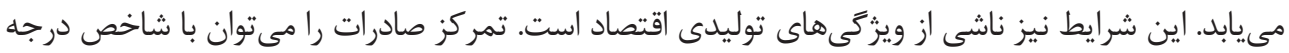

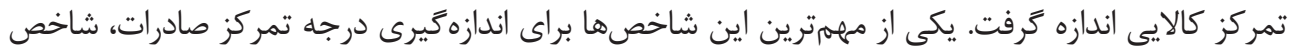

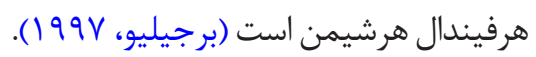

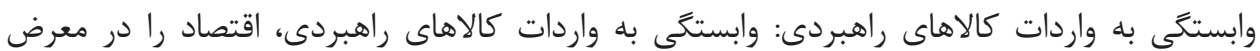

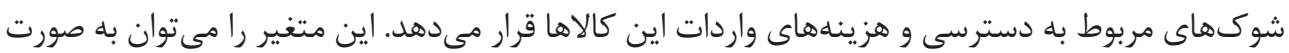

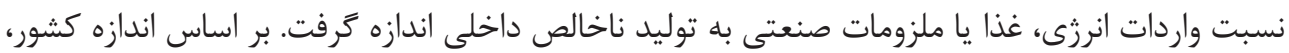

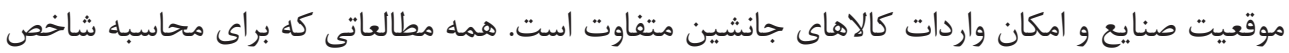

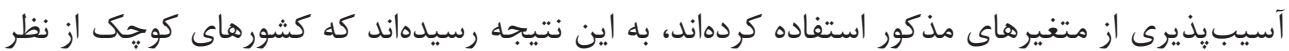
اقتصادى آسيبيذيرتر از كشورهاى ديخر هستند.

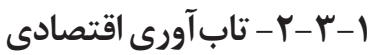

مفهوم مقاومت، در ادبيات موضوعى معادل تابآورى است و مقاومت اقتصادى يا اقتصاد مقاومتى نيز معادل إداد

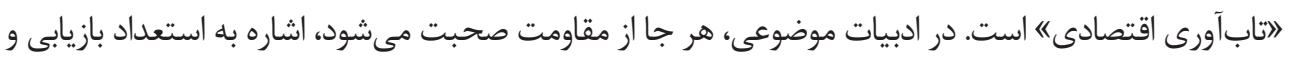

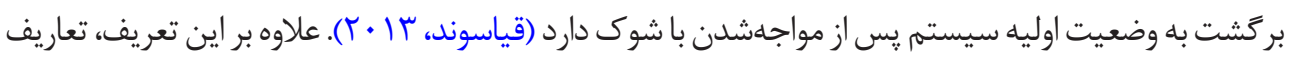

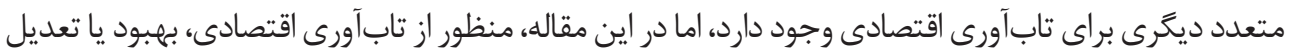
اثرات منفى شوك هاى بيرونى است.

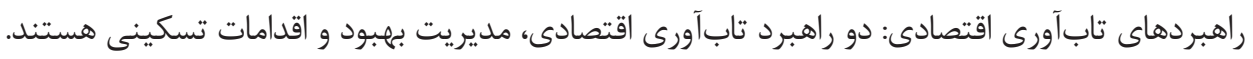

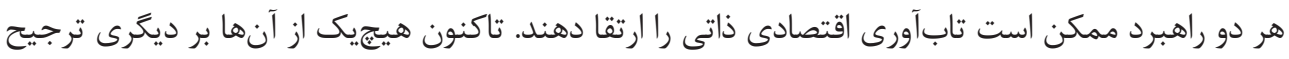

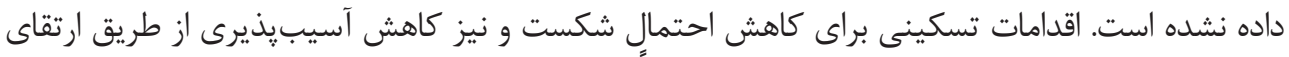

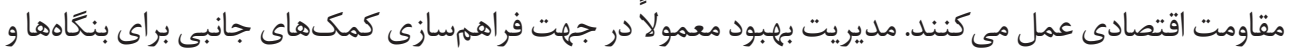

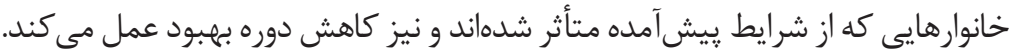

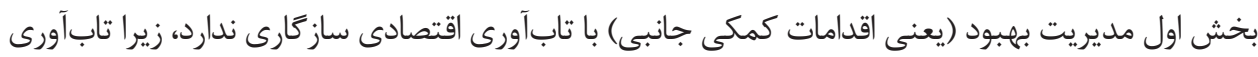

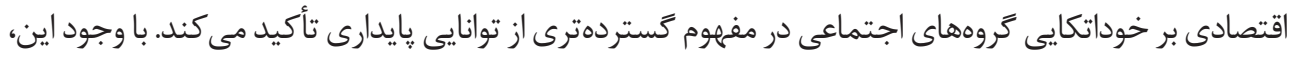


رهيافت كاهش دوره بهبود، نقش كليدى در توسعه مفهوم تابآورى اقتصادى براى دربركرفتن عناصر يويا دارد.

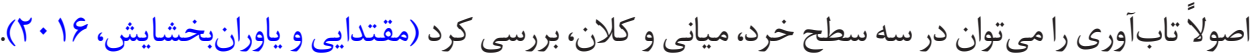

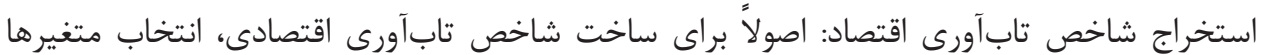

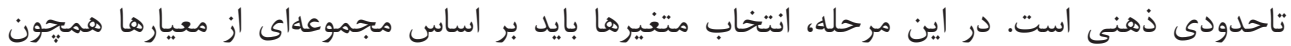

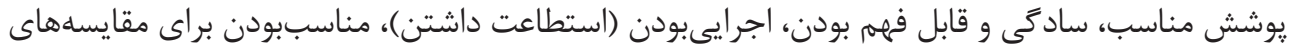

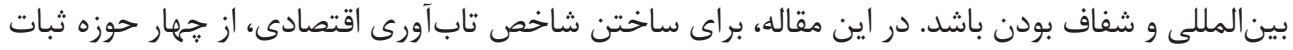

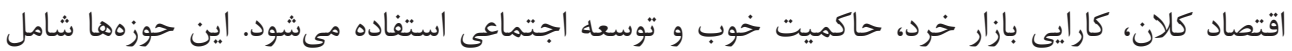

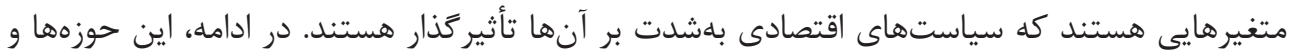

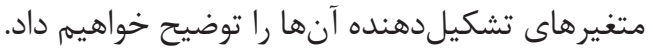

الف. ثبات اقتصاد كلان: اين حوزه به كنش و واكنش ميان عرضه و تقاضاى كل در اقتصاد مربوط مى بـ برود؛

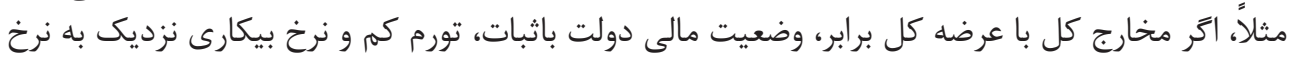

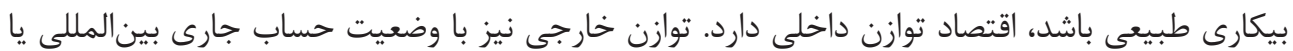

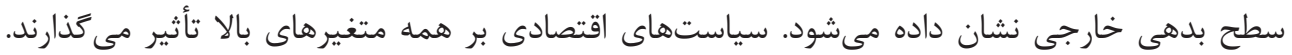

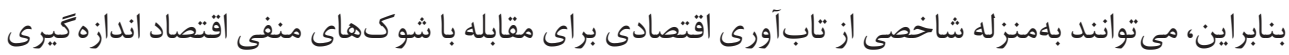

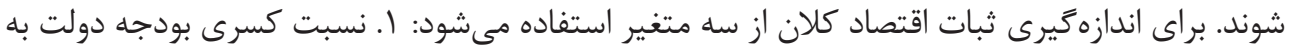

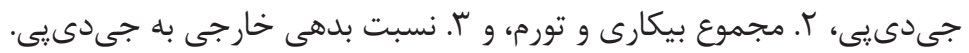

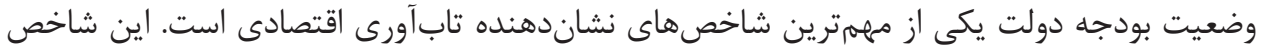

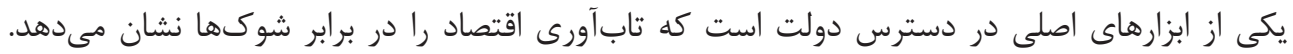

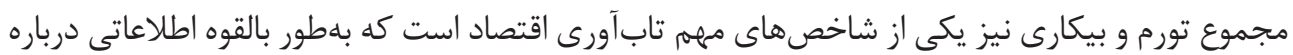

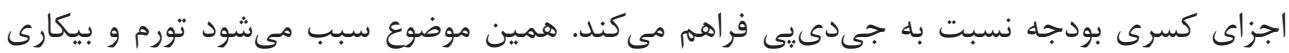

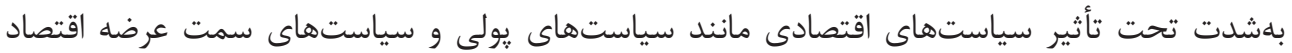

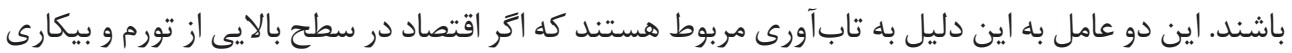

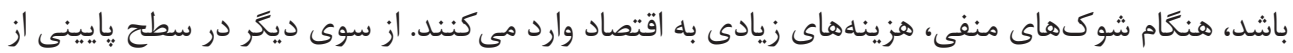

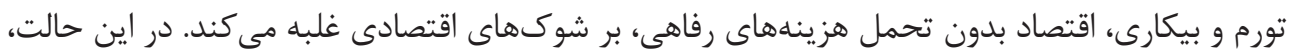

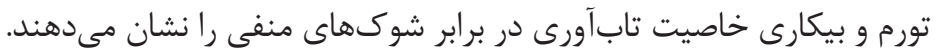

مجموع اين دو متغير كه با عنوان شاخص فلاكت اقتصادى شناخته مىشود، در اين مقاله بهمنزله شاخد

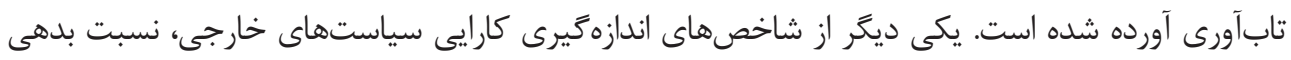

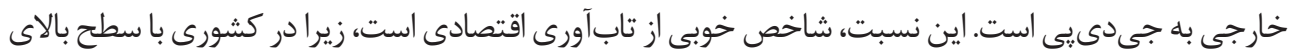

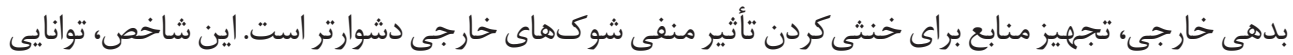

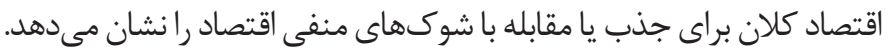


ب: كارايى بازار اقتصاد خرد: علم اقتصاد براى تخصيص منابع اقتصاد از فرايند قيمت استفاده مي كند.

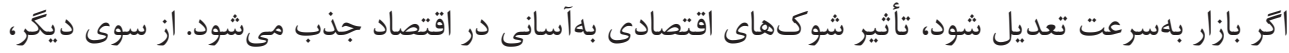

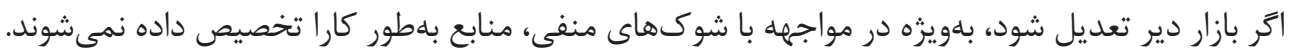

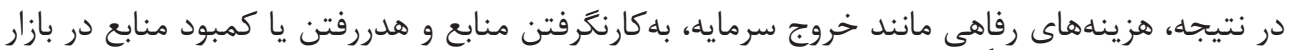

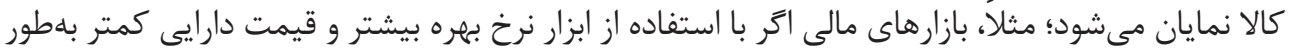

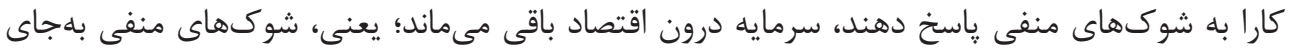

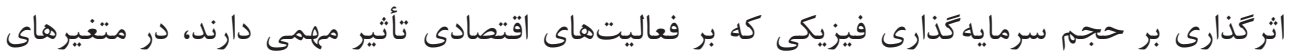

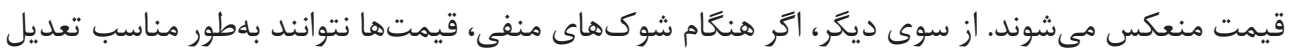

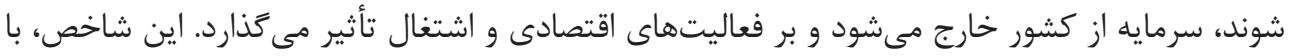

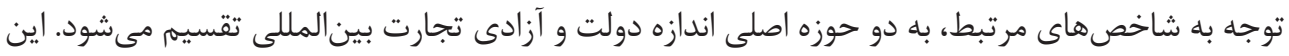

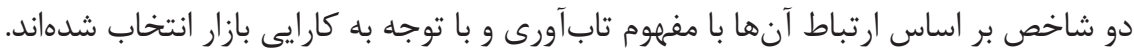

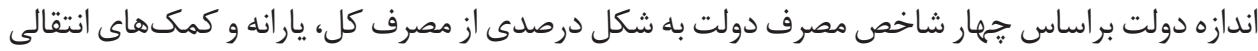

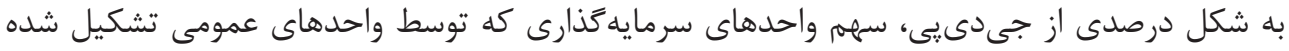

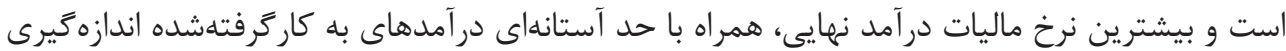

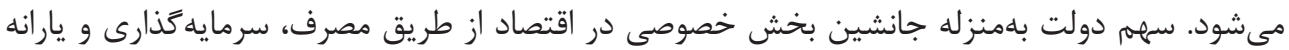

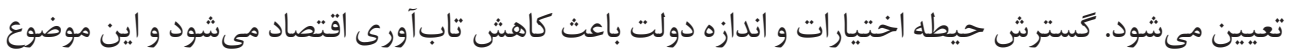

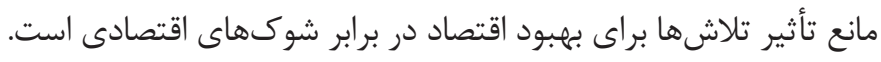

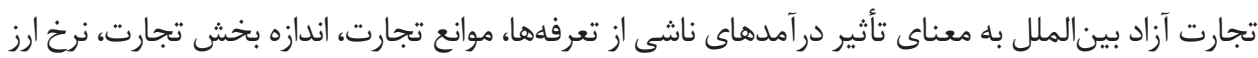

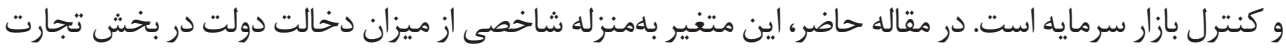

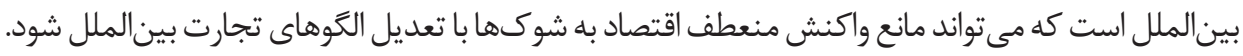

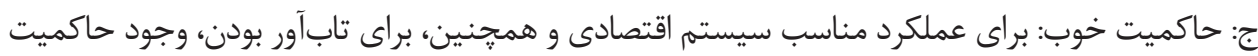

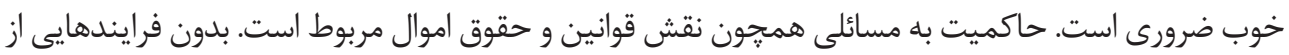

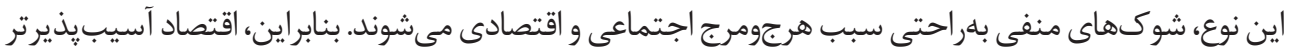

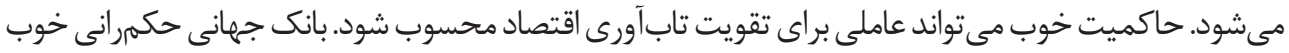

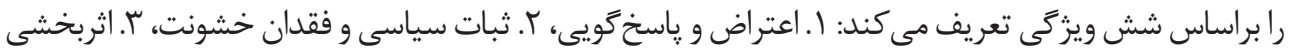
دولت، أ. كيفيت مقررات، ه. حاكميت قانون، و و. كنترل فساد.

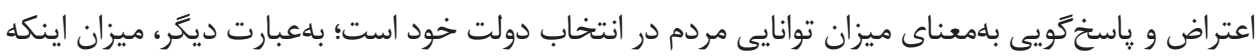

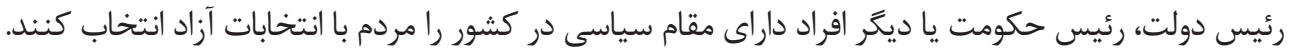

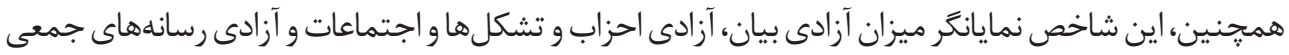

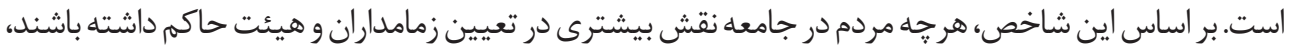

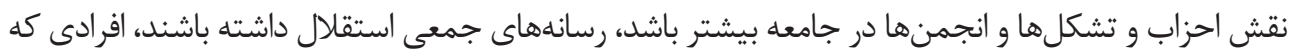


زمامدار جامعه هستند و در جامعه قدرت دارند، ياسخ گَىى اعمال خود باشند و افراد مختلف بتوانند آزادانه فعاليت كنند و نظر خود را بخويند، نشاندهنده وضعيت بهترى از حكمرانى خوب است (كافمن و همكاران، ؟ + . ب). ثبات سياسى و نبود خشونت، بيانگر احتمال سرنكونى حكومت و نظام سياسى به شيوههاى غيرقانونى يا با

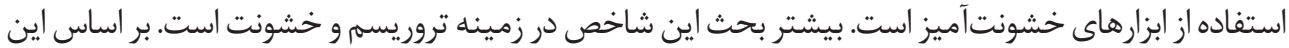

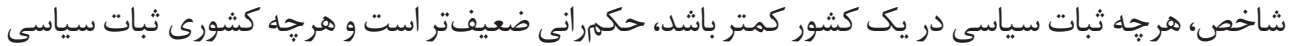

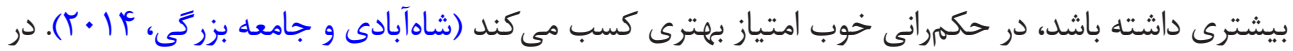

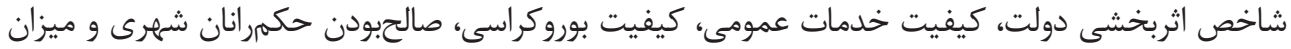

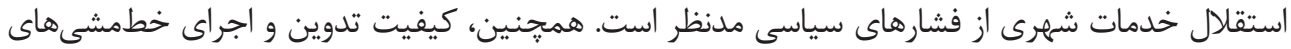

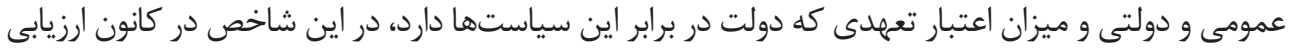

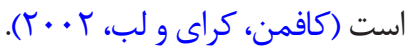

در كيفيت مقررات، بر مفهوم كنترل قيمتها، نظارت بر نظام بانكى و مواردى همجون فشارنياوردن به صاحبان

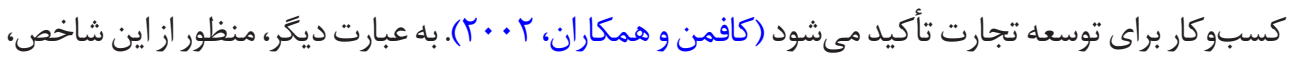

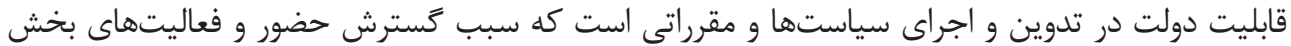

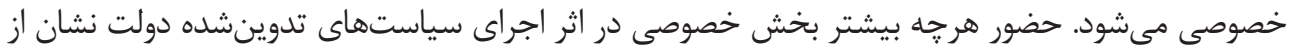

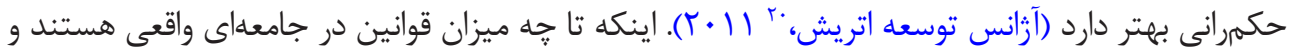

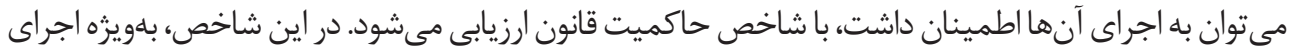

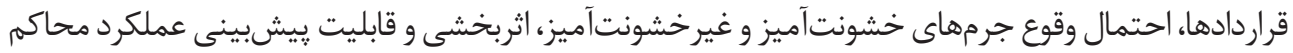

$$
\text { قضايى در جامعه بررسى مىشود (كافمن و همكاران، ب + . r). }
$$

فراوانى "يرداختهاي اضافى براى انجام كارهاه جنبه قابل تأمل در بخش كنترل فساد است. به عبارت ديخر،

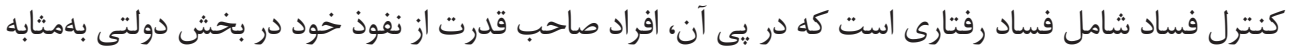

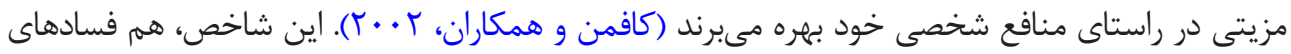

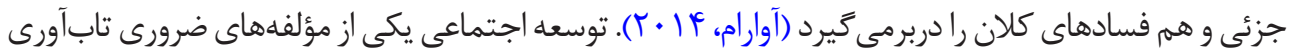

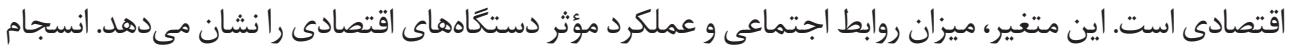

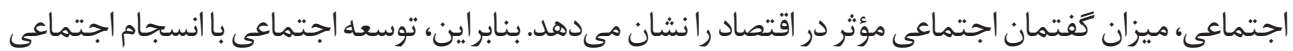

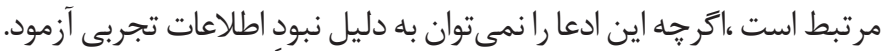

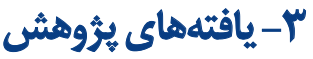

در اين بخش، شاخص تركيبى آسيبيذيرى و تابآورى اقتصادى در اقتصاد ايران در دوره زمانى سالهاى

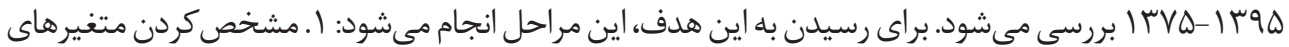
20. Austrian Development Agency 


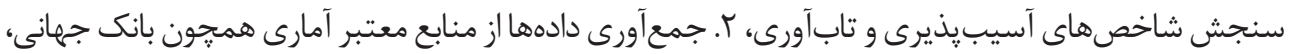

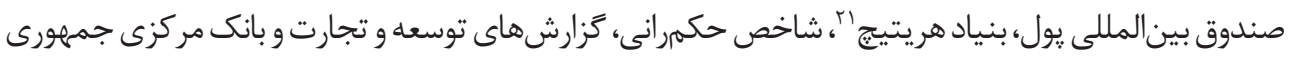

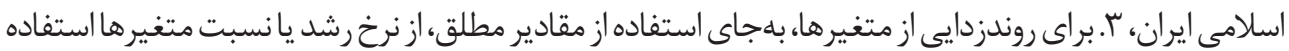

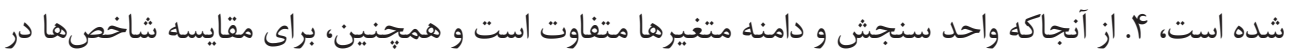

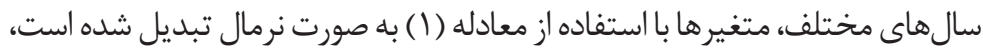

$X S_{i t}=\left(\mathrm{X}_{i t}-\min X_{i}\right) /\left(\max X_{i t}-\min X_{i t}\right)$

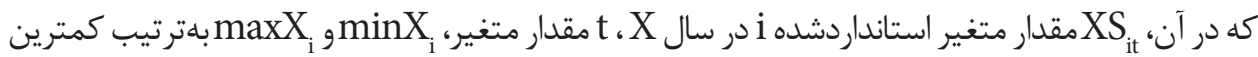

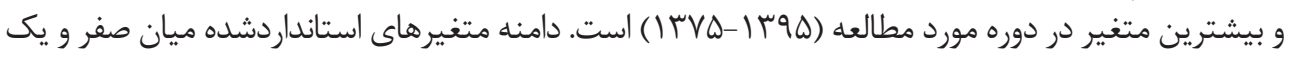

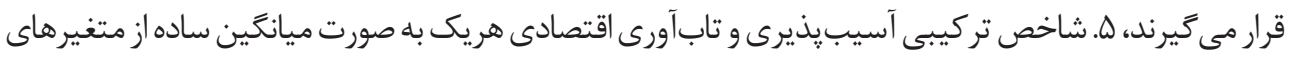

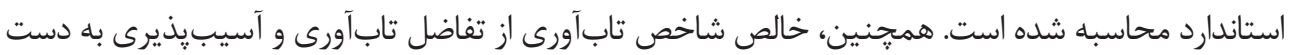

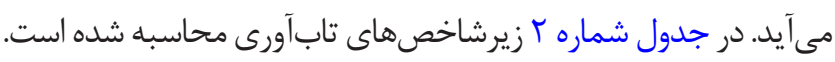

بر اساس جدول شماره T و تصوير شماره T دو زيرشاخص توسعه انسانى و حاكميت خوب، نقش بيشترى در

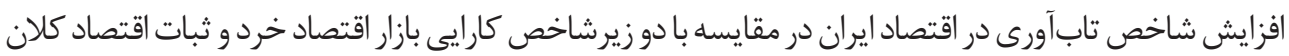

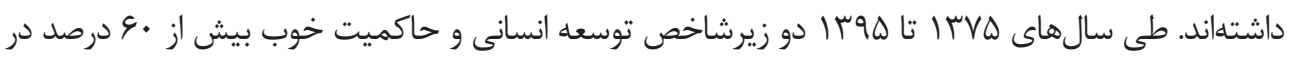

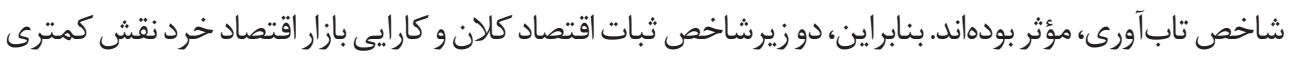

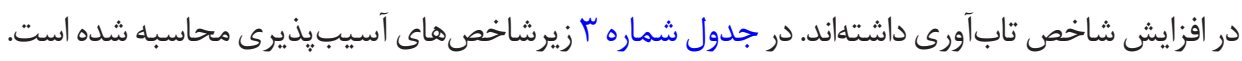

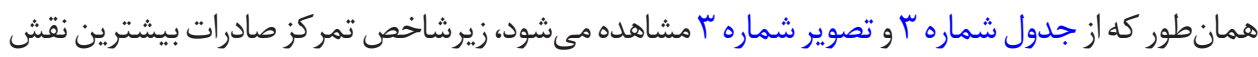

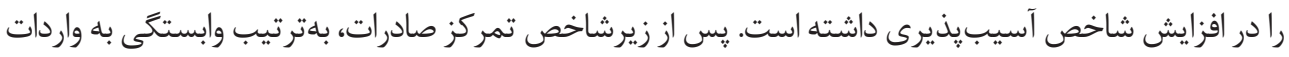

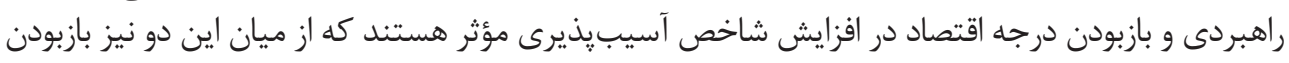

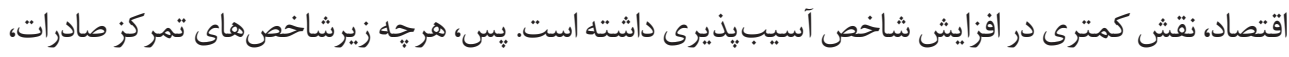

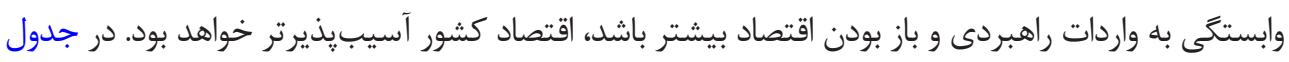

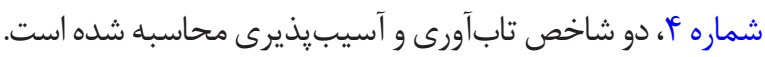

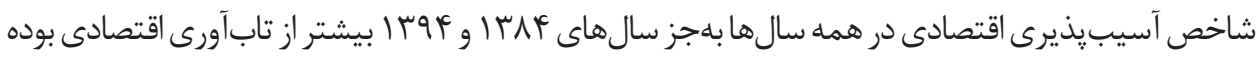
كه نشاندهنده افزايش آسيبزيذيرى كشور در اقتصاد ايران در اين سالهاست (جدول شماره أ و تصوير شماره

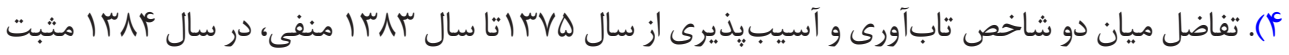

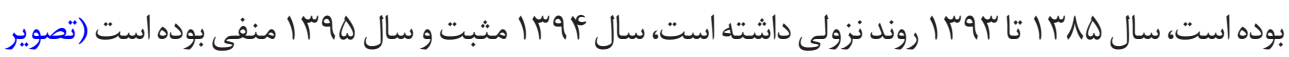




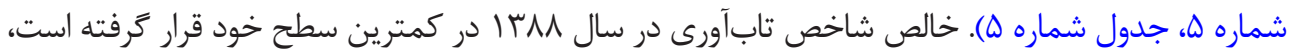

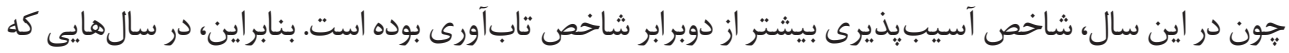

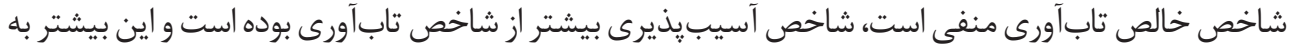

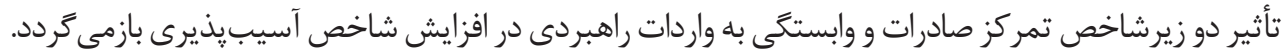

\section{ع- ع بحث و نتيجليَيرى}

يكى از مهممترين ابعاد اقتصاد مقاومتى، تابآورى اقتصاد ملى دربرابر تغييرات، مخاطرات و تهديدهاى داخلى

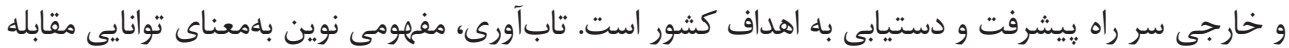

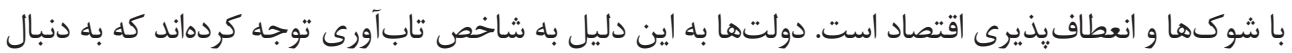

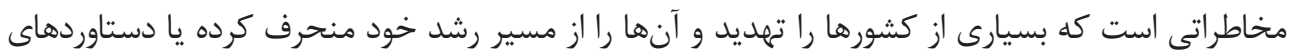
توسعهشان را نابود كرده است.

توانايى مقاومت اقتصاد در برابر عوامل تهديدزاى درونى و بيرونى يكى ديخر از شاخصهاى اقتصاد

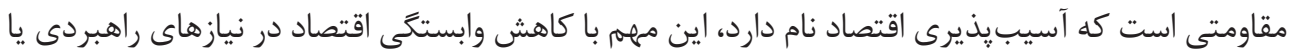

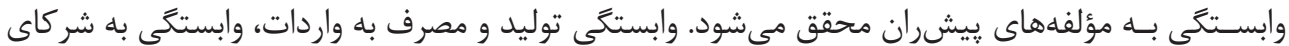

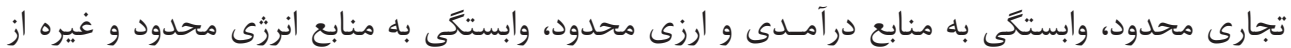
مصاديق آسيب پِيرى اقتصاد هستند. با توجه به تأثير زذارى اين دو شاخص بر اقتصاد كشورها بهويزه اقتصاد كشورهاى درحالتوسعه، اهميت

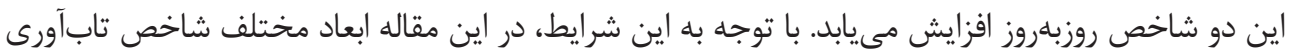

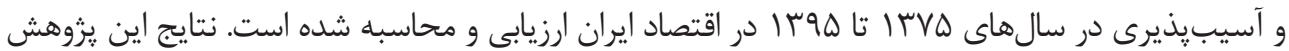

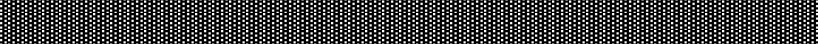

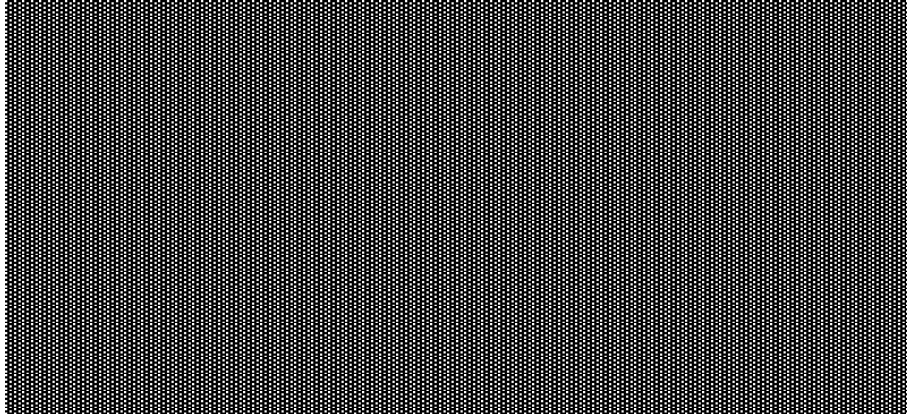

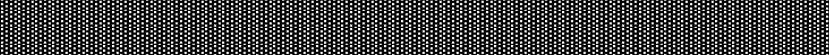

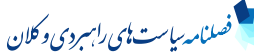

تصوير r. زيرشاخصهاى تابآورى در اقتصاد ايران (مثبع: محاسبات يرّوهش) 
جدول r. برآورد زيرشاخصهاى ثاب آورى در اقتصاد ايران

\begin{tabular}{|c|c|c|c|c|}
\hline شاخص/مال & كارايي بازار اقتصاد خُرد & توسعه انسانى & ثبات اقتصاد كلان & حاكميت خُوب \\
\hline IIVA & -/MPFeAVTre & . IEPT & - /IIEAY+9TA & - IFAFY.VAPA \\
\hline Irve & - IITTEAAF+1 & - IEPA & -1.r+rofAr & $.18819+.179$ \\
\hline irw & H. Finafffff & - lear & . HWvear & . (8тququrir \\
\hline Im & -/TMFETrqI & .198 & l.VEIVIqAT & - legavat+A \\
\hline irva & $. / M A q F+|K F|$ & .1898 & . 1.8 FarVFAl & . lgatillfita \\
\hline IrA. & -/rmeq. & $+18 n^{2}$ & $+11+1891119$ & $\cdot N+$ HVE+ATA \\
\hline $\mid$ MNA| & +189trmaqs & $.18 v 9$ & I.\&NDAQS\&V & $\cdot N(\Delta F+V T+V$ \\
\hline IrAT & -/rentrtare & - $18 N$ & \% AVqAMTf & $\cdot / N+98 \mid 11 Y$ \\
\hline IrAN & ./TAFVQRTQ & - IEAY &.$+\Delta S T \cdot P F Y^{L}$ & $. N+\Delta 1 V+19 f$ \\
\hline IFAF & $+18 \cdot 9 \Delta \Delta+\Delta W$ & . Isar & $.1 .1 \cdot \Delta \Delta T M T$ & - /FTaIAFafF \\
\hline IHAD & $+/ 4+$ SVESVIA & $\cdot N+F$ & . FAAPVTI & $. / F 999 \Delta+.+F V$ \\
\hline ITNE & - IVAFa.+V &.$/ M I S$ & $.1 .899114 T W$ & - /FADAF+YUA \\
\hline ITAV & $.10 .9 M T T \Delta \Delta Q$ & $\cdot / r r \alpha$ & ./NTT99Y.94 & - /FFASNAQY \\
\hline$I r M$ & $.1 .98 \times 9 r \cdot 11$ & . MTA & . . VI9qEATY & . ravege.r \\
\hline IrAq & . $/$. 1. esa.r & . $M P A$ & . FAnTe+pi & - ITVEETIITA \\
\hline irq. & ./mr"seqIme &.$N \Delta \Delta$ & .1 .940940 & - reqIVNeAT \\
\hline$|r q|$ & - Mevaias & - Neq & . /19MIADFq & . ME. VAATES \\
\hline Irar & - Metrthata &.$M W$ & - /енетт人я११ & ./rA.VIqQA \\
\hline שצ"r & $.|P| \cdot|A| r \mid$ &.$/ M$ & - Mirfream & $\cdot|\Delta \cdot V T| \cdot \Delta Q$ \\
\hline Irap &.$/ N \cdot 0.9 \cdot 918$ &.$/ M{ }^{2}$ & - MAETIATqF & - IAADIITVIAS \\
\hline $1 \% 90$ & $\cdot \mid A \cdot \Delta \cdot 191 \pi T$ & - NOV & - IEVTAFTYAR &.$/ 111011$ \\
\hline
\end{tabular}




\begin{tabular}{|c|c|c|c|}
\hline شاخص/ سال & شاخص ثمركز صادرات & وابستكي به واردات راهبردى & بازبودن اقتصاد \\
\hline Irvo & $\cdot M e r$ & 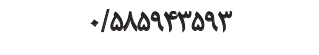 & - RAPF. FATQ \\
\hline irve & . Isqu & 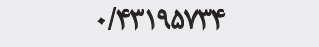 & $.|A T| . . \Delta M r$ \\
\hline irw & . Ifre & ./Trvari.9r & - pqripikq.r \\
\hline Irva & . IErr & -/FFtata.mT & - /oroivaur \\
\hline ima & •/var & - IgAATHETA & $\cdot / p+r e+16 q$ \\
\hline Iru. & $+/ W A$ & $\cdot \mid \Delta P \cdot T V \cdot M T Y$ & -/aralauma \\
\hline $\mid$ 피 & $+/ V \Delta$ & - Neifatirt & - MRYGQATNE \\
\hline irar & $\cdot m^{*}$ & - Meq1a.pra & - MMFEV.AF \\
\hline irkr & . NES & $\cdot / 8 V A \cdot M F \cdot \Delta A$ & . /FeqRTE. re \\
\hline IMNe & . IVEV & 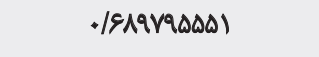 & $. / R A M I .8 \mid V^{n}$ \\
\hline IrAo & - Mar & - MIEAT-Mff & - Rrtariqsaq \\
\hline IrNe & . Neg & -/VRAVAVETTa & . MAOntries \\
\hline ITAV &.$/ M T$ & - /8I9AHIEAF & - prefeatret \\
\hline IrM &.$M m p$ & .Mrega.qmI & - /AETIEATEA \\
\hline Irkq & . Iere & - Magriata & - M. THVAIEA \\
\hline ima. & .1810 & .MIAT+\&OI & -/FarqifaAr \\
\hline$|r q|$ & + IErr & - /ATIVA.VIA & .MTIIgrarI \\
\hline Irat & $\cdot / \Delta V \mid$ & - IRTTAFAQRT & . MTEDAYY.MF \\
\hline rer & $\cdot / \Delta V \mid$ & -/AIETATVAE & $. / 47 q u+198$ \\
\hline Imqp & $.|8| \mid$ & - /AMT+19HAP & - PATMTYII \\
\hline 1790 & $.10 \%$ & - NorTEA. \&D & - / \\
\hline
\end{tabular}



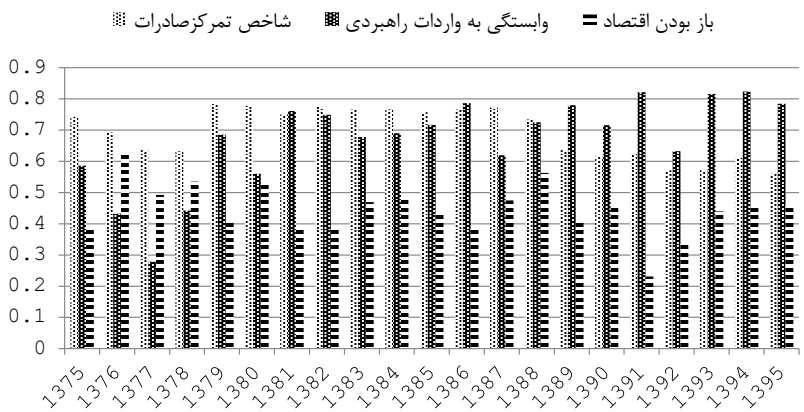

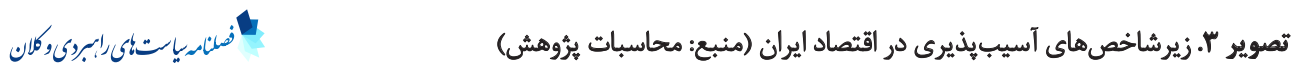

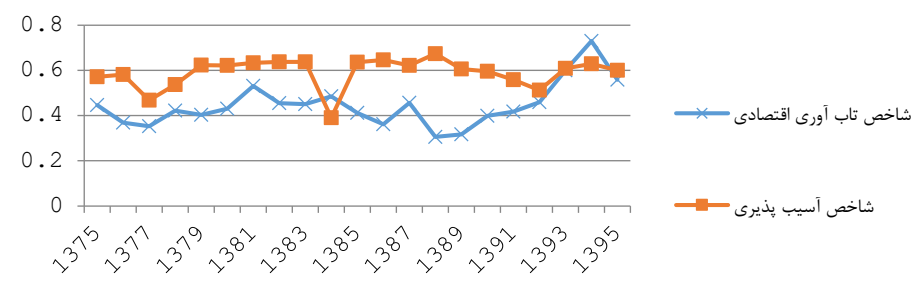

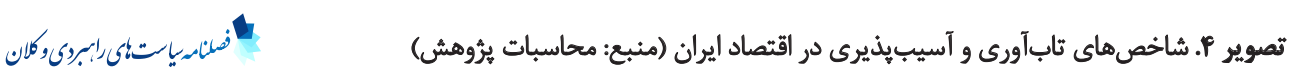

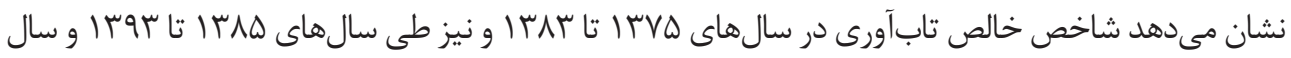

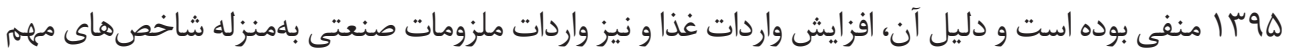
آسيب ڤِيرى بوده است.

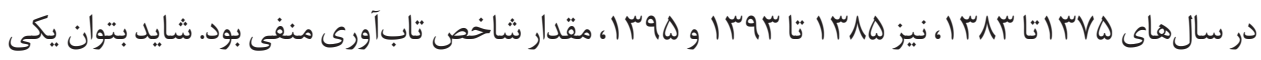

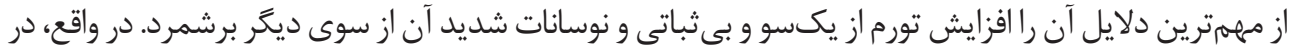

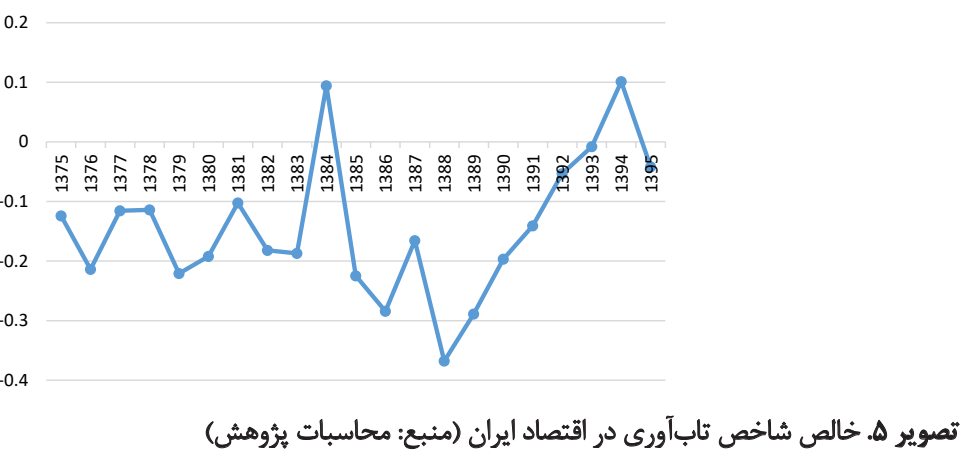

|ct

تصوير ه. خالص شاخص ثابآورى در اقتصاد ايران (منبع: محاسبات يثروشش) 
جدول †. برآورد شاخص ثابآورى و شاخص آسيبيذيرى در اقتصاد ايران

\begin{tabular}{|c|c|c|}
\hline شياخم/سال & شاخص آسيبيذيرى & شاخص تابآورى \\
\hline Irvo & $.10 \mathrm{~V} 111 \mathrm{E} \cdot \mathrm{rr}$ & - Arequiaro \\
\hline inve & - $(\Delta A 1) A W \cdot P$ & - REAY.rQ.V \\
\hline im & - Meavasese & - ITARTAAMT \\
\hline irva & - /ArEAEATH & - ATTRAKT+AI \\
\hline imq & 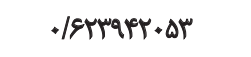 & . Me rNe.var \\
\hline IrA. & - Iermprerer & . ATH. MTTRTOS \\
\hline$|r|$ & .18 mriqu.q & $\cdot\left|\Delta H^{\prime}\right| r \Delta \cdot V \mid$ \\
\hline IrAT & - IETVT- DADP & - lisatradar \\
\hline irar & . IFtVAY..rI & - /Pa.varves \\
\hline IrAf & $. / 4 q . q R T P 1$ & . PAATrt..1 \\
\hline ITAD & - Irreapermp & $. / P \| E P I . . r$ \\
\hline IrNe & - IEPAAMIETY & . KEIVTEY.1 \\
\hline IrAV & . /8т1994 & $. / P \Delta E I . r I P q$ \\
\hline IrM & . IFVrqar.8A & $\cdot M+q+r+P I E$ \\
\hline iraq & . 18. DQTYTrY & $\cdot / M I V I \cdot \Delta \Delta r$ \\
\hline imq. & 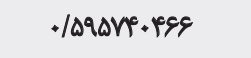 &.$/ \% 99$. NQq18 \\
\hline 1191 & - IDANETADF & 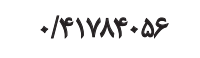 \\
\hline Irar & - $/ \Delta 1 Y$ - YQREA & $.1909 \Delta 4.999$ \\
\hline ז" & $.18 \cdot 9 \cdot \Delta P T H R$ &.$|8 \cdot .9 \Delta V| \cdot P$ \\
\hline irqp & - IEтAQRIU & $. / n+11 m i v e$ \\
\hline 1790 & $.18+0 \Delta A q 4+r$ & 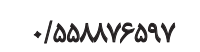 \\
\hline
\end{tabular}

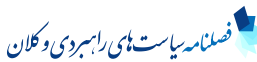

منبع: محاسبات بُروهُش 


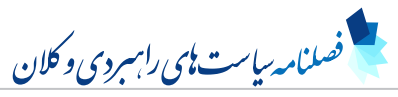

جدول ه. خالص شاخص ثابآورى

\begin{tabular}{|c|c|}
\hline شاخص/سال & شاخص تابآَورى \\
\hline irva & -./MPIITEAIT \\
\hline ITVE & -./TITVAFIQY \\
\hline itr &.$- / 110 \Delta r v a q f$ \\
\hline IrVA & -./IIT99VهดY \\
\hline Irvq & $-. / M T I+1|| r E \mid$ \\
\hline irs. & -./194IFramr \\
\hline$|r A|$ & -*/. \\
\hline IHAT & $-+/ 119 \Delta \mathrm{VTV}$ \\
\hline זMAM & -./NAV.TVYEA \\
\hline IrAF & . 1.9TTAPVE \\
\hline IHAD & $-\cdot / M F F q \cdot \Delta C H I$ \\
\hline IHA & - . MAF-QDFHI \\
\hline IHAV &.$- / 18049118 V$ \\
\hline IMM & -./TEVATISTa \\
\hline Irkq & -./TMUVEVIV \\
\hline irq. & $-/ / 989 \Delta T^{\prime} \Delta \Delta$ \\
\hline$|r q|$ & $-+/ 14+$ raqu \\
\hline Irar & $-.1 . \Delta m p e q 1$ gq \\
\hline irqu & $-.1 \cdot+1 \cdot 9 \mathrm{VTr}$ \\
\hline Iraf & $+/ 1 \cdot 11 F \Delta 9 V A$ \\
\hline $1 \% 90$ & $-.1 . p i v i r .00$ \\
\hline
\end{tabular}

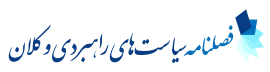

منبع: محاسبات ثئروهش 
اين دورهها تورم زياد و نوسانات آن، هزينههاى زيادى را بر اقتصاد كشور تحميل كرد؛ تورم زياد و بىثبات باعث

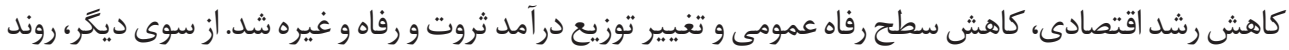

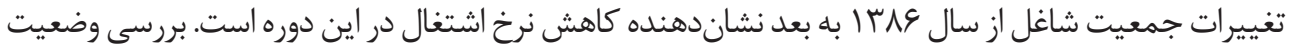

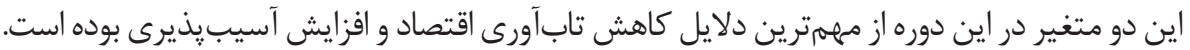
در سال \& q ا ميزان خالص تابآورى مثبت شد. يكى از دلايل مهرم افزايش تابآورى در اين سال تحريمهاى

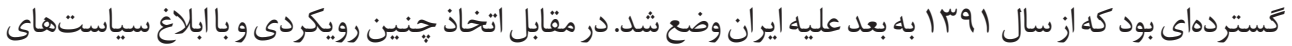

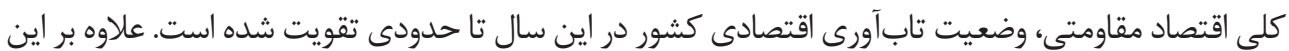

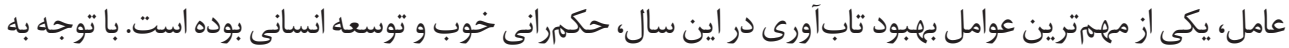

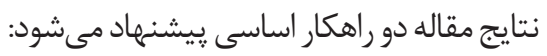

سياست گذاران با شفافسازى اطلاعاتى و غيراطلاعاتى بازارهاى كسبوكار داخلى، ايجاد ثبات در بازار و

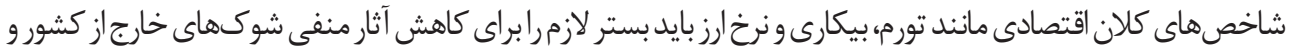

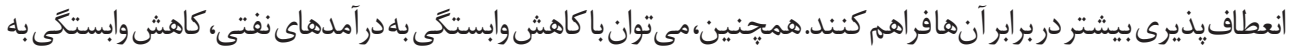

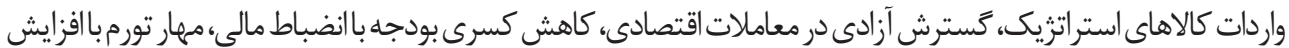

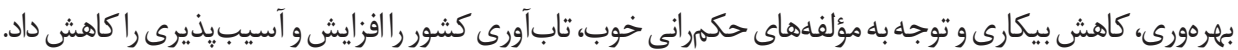

ملاحظات اخلاقى

$$
\text { مامي مالى }
$$$$
\text { تمام نويسند }
$$$$
\text { تعارض منأفح }
$$

بنا به اظهار نويسندَان، در اين مقاله هيجزَّنه تعارض منافعى وجود ندارد. 


\section{References}

Abounoori, E., \& Lajevardi, H. (2016). [Estimated the index of economic vulnerability and resilience using parametric method: The case (Persian)]. Applied Theories of Economics, 3(3), 25-44.

Angeon, V., \& Bates, S. (2015). Reviewing composite vulnerability and resilience indexes: A sustainable approach and application. World Development, 72, 140-62. [DOI:10.1016/j.worlddev.2015.02.011]

Austrian Development Agency. (2011). Evaluation of the Austrian Development Cooperation (ADC) gender policy between 20042011. Vienna: Austrian Development Agency.

Avram, C. (2014). Good governance and doing business: Evidence from a cross-country Survey. Transylvanian Review of Administrative Sciences, 41, 27-46.

Bates, S., Angeon, V., \& Ainouche, A. (2014). The pentagon of vulnerability and resilience: A methodological proposal in development economics by using graph theory. Economic Modelling, 42, 445-53. [DOI:10.1016/j.econmod.2014.07.027]

Boorman, J., Fajgenbaum, J., Ferhani, H., Bhaskaran, M., Arnold, D. \& Kohli, H. A. (2013). The centennial resilience index: Measuring countries resilience to shock. Global Journal of Emerging Market Economies, 5(2), 57-98. [DOI:10.1177/0974910113494539]

Briguglio, L. (1997). Alternative economic vulnerability indices for developing countries. New York: United Nations Department of Economic and Social Affairs.

Briguglio, L. (2004). Economic Vulnerability and Resilience: Concepts and Measurements. In L. Briguglio \& E. J. Kisanga (Eds.), Economic Vulnerability and Resilience of Small States (pp.1-20). Msida, Malta: University of Malta.

Briguglio, L., \& Galea, W. (2003). Updating and augmenting the economic vulnerability index. Msida, Malta: Island and Small States institute.

Briguglio, L., Cordina, G., Farrugia, N., \& Vella, S. (2009). Economic vulnerability and resilience: Concepts and measurements. Oxford Development Studies, 37(3), 229-47. [DOI:10.1080/13600810903089893]

Cordina, G. (2004). Economic vulnerability and economic growth: Some results from a neo-classical growth modelling approach. Journal of Economic Development, 29(2), 21-39.

Farrugia, N. (2004). Economic vulnerability: Developing a new conceptual framework and empirically assessing its relationship with economic growth $[\mathrm{PhD}$. dissertation]. Msida, Malta: University of Malta.

Forooghi Zadeh, Y. (2014). [The conceptual explanation of resistance economics and indicating and measuring the resiliency of the iranian economy (Persian)] [MSc. thesis]. Tehran: Imam Sadiq University.

Ghiasvand, A. (2013). [A report on general policies for resilient economy, an overview of global literature on national reconciliation (Persian)]. Tehran: Economic Studies.

Ghiasvand, A., Abdolshah, F. (2016). [The concept and measurement of economic resilience (Persian)]. Economics Research, 15(59), 161-87.

Kaufmann, D., Kraay, A., \& Lob, P. (2002). Governance matters II: Updated indicators for 2000-01. Washington: World Bank.

Manyena, S. B. (2006). The concept of resilience revisited. Disasters, 30(4), 434-50. [DOI:10.1111/j.0361-3666.2006.00331.x] [PMID] 
Martin, R. (2012). Regional economic resilience, hysteresis and recessionary shocks. Journal of Economic Geography, 12(1), 1-32. [DOI:10.1093/jeg/lbr019]

Moghtadaei, A., \& Yavaran Bakhshayesh, A. (2016). [Analysis of the causal relationships between indicators of general policies of resistive economy by utilizing multiple criteria Decision Making ( DEMATEL approach) (Persian)]. The Macro and Strategic Polics 4, 33-62.

Paton, D., \& Johnston, D. (2013). Disasters and communities: Vulnerability, resilience, and preparedness. Disaster Prevention and Management, 10(4), 270-7. [DOI:10.1108/EUM0000000005930]

Rose, A., \& Krausmann, E. (2013). An economic framework for the development of a resilience index for business recovery. International Journal of Disaster Risk Reduction, 5, 73-83. [DOI:10.1016/j.ijdrr.2013.08.003]

Rose, A. (2004). Defining and measuring economic resilience to disasters. Prevention and Management: An International Journal, 13(4), 307-14. [DOI:10.1108/09653560410556528]

Shahabadi, A., \& Jamebozorgi, A. (2014). [Theory of good governance from Imam Ali, s (AS) perspective (Persian)]. Journal of Nahjolbalagha, 1(2), 1-17. 